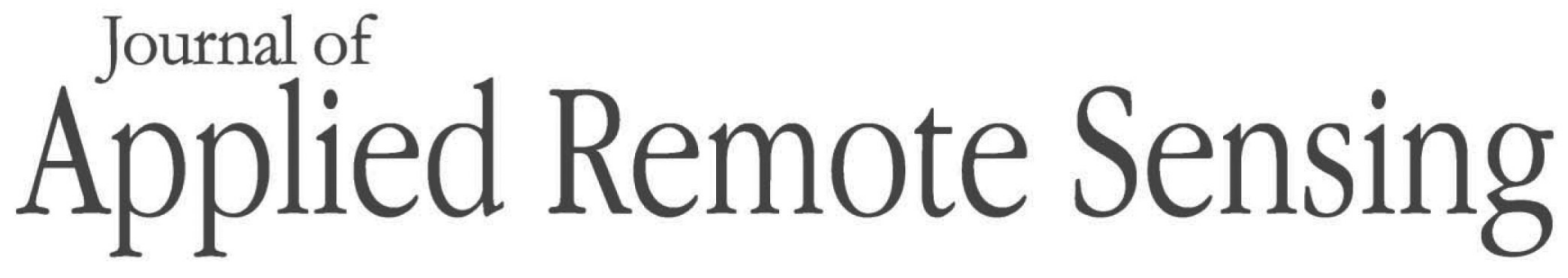

\title{
Investigation and comparison of land-cover change patterns in Xuzhou city, China, and Dortmund city region, Germany, using multitemporal Landsat images
}

Cheng Li

Nguyen Xuan Thinh 


\title{
Investigation and comparison of land-cover change patterns in Xuzhou city, China, and Dortmund city region, Germany, using multitemporal Landsat images
}

\author{
Cheng Li and Nguyen Xuan Thinh \\ TU Dortmund University, Faculty of Spatial Planning, Department of Spatial Information \\ Management and Modelling, August-Schmidt-Strasse 10, 44227 Dortmund, Germany \\ cheng.li@tu-dortmund.de; nguyen.thinh@tu-dortmund.de
}

\begin{abstract}
Analyzing spatiotemporal characteristics of land-cover (LC) change is important for assessing environmental consequences of urban growth and supporting land management and planning. Less attention, however, has been given to the comparison between land-cover change patterns in developing and developed countries. In this study, Xuzhou city and Dortmund city region were selected as study areas. Multitemporal Landsat images were classified by using the integration method of maximum likelihood classifier, subpixel classifier, and multiple normalized difference vegetation index values based on Vegetation-Impervious Surface-Soil model. Urban growth patterns and processes of the two study areas were investigated and compared through land-cover change detection, buffer analysis, and jaggedness degree. The results indicated that the urban area in Xuzhou city increased more than threefold dramatically from 128.5 to $418.3 \mathrm{~km}^{2}$, and the increased sprawling development trend was observed during the study period, while Dortmund city region showed a slight increase from 498 to $715.5 \mathrm{~km}^{2}$ in urban areas with an increasingly compact development trend. The results revealed a notable difference of spatiotemporal land-cover pattern dynamics between the two study areas as well as confirmed the effectiveness of the combined method of remote sensing and spatial analysis that can be used to support land management and policy decisions. (c) 2013 Society of Photo-Optical Instrumentation Engineers (SPIE) [DOI: 10.1117/1.JRS.7.073458]
\end{abstract}

Keywords: land-cover change; urban growth pattern; Landsat; vegetation-impervious surfacesoil model; buffer analysis; jaggedness degree.

Paper 13172 received May 17, 2013; revised manuscript received Nov. 19, 2013; accepted for publication Nov. 25, 2013; published online Dec. 23, 2013.

\section{Introduction}

In recent decades, urban growth has been accelerating with the massive immigration of population to cities. ${ }^{1}$ The majority of urban growth occurs in developing countries, while it also continues in developed countries, although at a much slower rate on average than in the previous decades. Like other developing countries, China experienced a rapid development in recent decades; land-cover (LC) pattern has been dramatically changed, especially with regard to urbanization and loss of cultivated land. It caused a series of environmental and socioeconomic problems, which significantly threaten the sustainable development. ${ }^{2,3}$ Consequently, the planning and management of urban areas become more complex and difficult. Given the importance of the long-term effect of urban growth, analysis and monitoring of LC change have attracted international attention. ${ }^{4-6}$ The accurate assessment of urban growth has become increasingly necessary not only for understanding the environmental impacts, but also for providing supports to the implementation of sustainable urban development policy. Less attention, however, has been given to the comparison between LC change patterns in developing and developed countries. Hence, there is a need to compare and analyze the differences between spatiotemporal urban patterns in developing and developed countries in order to provide valuable information

0091-3286/2013/\$25.00 @ 2013 SPIE 
for understanding the urbanization process as well as for supporting sustainable development planning in developing countries.

Analyzing and mapping both the present LC status as well as the LC changes over the time are recognized as important methods to solve the problems caused by significant land-use change. ${ }^{7,8}$ Remote-sensing data are the most common data source for detection, quantification, and mapping of LC change patterns. ${ }^{9}$ It provides a great amount of information on the geographic distribution of LC change, along with the advantages of cost and time saving for regional size areas. ${ }^{10}$ The LC change information can be gained from remote-sensing data by applying a variety of techniques such as visual interpretation, LC classification, and change detection. Furthermore, urban growth pattern can be detected and quantified by buffer analysis using geographic information system (GIS) and urban pattern analysis, both of which offer insights into the urbanization process and spatiotemporal urban growth pattern for study areas. The combination of remote sensing (RS) and spatial analysis can provide detailed information about landuse change and urban growth pattern, allowing for a better understanding of urban growth processes. ${ }^{11}$

The aim of the research is to investigate and compare the LC change and the dynamics of urban expansion in Xuzhou city, China, and Dortmund city region, Germany, using the integrated change pattern detection and analysis methods. The specific steps are, using multitemporal Landsat data: (1) to extract historical LC information for the investigation areas through the classification of remote-sensing images; (2) to reveal and compare the LC change trends in the two study areas during the study period; and (3) to analyze and compare between the urban growth patterns in the two study areas. The primary focus was on urban development in Xuzhou; we expected that the analysis of urbanization pattern in Dortmund city region can be considered helpful for sustainable development of Xuzhou.

\section{Study Areas and Data}

\subsection{Study Areas}

Two study areas (Fig. 1) were selected for this study. Xuzhou city in China is located in the eastern part of China in the plains of Yellow River and Huaihe River with an administrative area of $11,258 \mathrm{~km}^{2}$. It is regarded as a medium-sized metropolitan area in comparison to

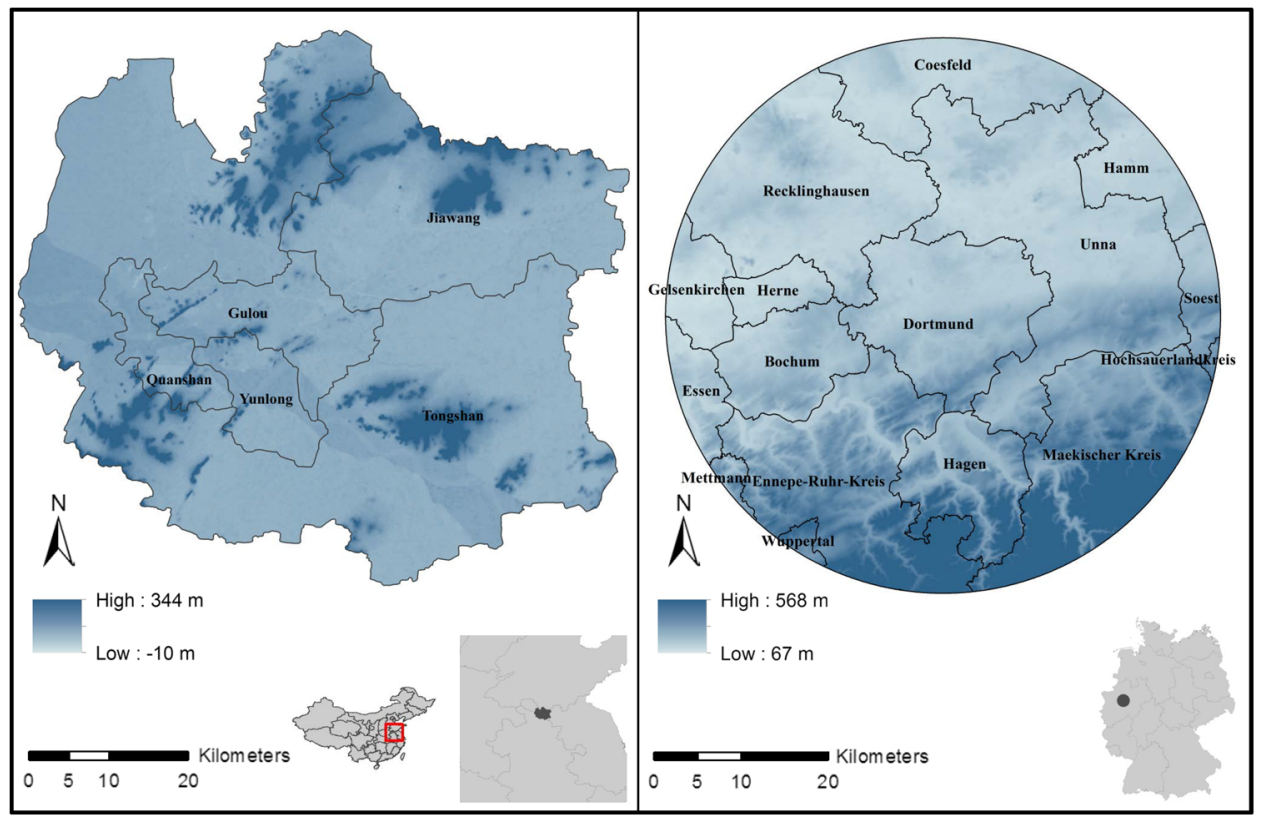

Fig. 1 Study areas and locations (Data: DEM). 
other cities in China. Xuzhou city is composed of five districts (Quanshan, Gulou, Yunlong, Jiawang, and Tongshan), in which the first three districts are viewed as city centers. Mining and industrial manufacturing have been the source of the strong economic activity of the region. Xuzhou city is well known as one of the most important transportation hubs in China. Jinghu Railway (Beijing to Shanghai), Longhai Railway (Lianyungang to Lanzhou), and some other national main roads provide a good opportunity for development. Main LC types are built-up land, farmland, vegetation, and water body. Like other cities in China, Xuzhou has witnessed a rapid urbanization process and experienced fundamental LC change over the last two decades. According to Xuzhou's census, population of Xuzhou was 9.25 million in 2005, which represented an increase of 2.73 million people since $1979 .{ }^{12}$ The study area covers the city core and city fringe of Xuzhou city with the area of around $2897 \mathrm{~km}^{2}$ and the population of over 3 million inhabitants in 2005.

The second study area is located in German "Ruhr" region. With a population of some five million, Ruhr area is the largest urban agglomeration in Germany. The biggest city in Ruhr is Dortmund. The study area is defined as a circular area with the center in the city center of Dortmund and a radius of $30 \mathrm{~km}$. It covers the whole cities of Dortmund, Bochum, Hagen, and Herne and a part of cities including Essen, Wuppertal, Gelsenkirchen, and Hamm. It also covers some whole or a part of districts including Unna, Coesfeld, Soest, Maekischer Kreis, Ennepe-Ruhr-Kreis, Mettmann, Hochsauerlandkreis, and Recklinghausen. The total area of the study area is $2830 \mathrm{~km}^{2}$.

\subsection{Data}

In this research, Landsat MSS image, Landsat TM image, and Landsat ETM+ image (Global Land Cover Facility) under clear sky conditions were obtained and employed as the main data sources for providing LC information of study areas. More detailed information on the satellite data is given in Table 1. Numerous researchers have demonstrated the value of multitemporal imagery and auxiliary data for the classification of LC; they can improve RS classification accuracy, ${ }^{9,13,14}$ so some Landsat images acquired on other dates were also used. In order to assess the accuracy of classification results, a set of reference data was necessary, which included topographic maps, high-resolution aerial photography, and field survey data. Before being classified, the calculation of reflectance values, atmospheric normalization, and geometric correction had to be performed to make the images more interpretable. ${ }^{15}$ An improved atmospheric correction technique called cosine of the sun zenith angle was used to account for atmospheric transmittance along the path from the sun to the ground surface, which can generate more accurate results compared with the Dark Object Subtraction model. ${ }^{16}$ After atmospheric correction, all remotesensing images need to be geometrically corrected in order to enable correct area measurements, precise location, and multisource integration. All images were georeferenced using well-distributed ground control points and topographic maps. A second-order polynomial was then used, resulting in the root mean square errors of less than 0.75 pixels. The images were resampled to a pixel size of $30 \times 30 \mathrm{~m}^{2}$ using the nearest-neighbor algorithm to maintain the radiometric properties of the original data. ${ }^{17}$ Image processing was performed using ERDAS IMAGINE 2011 software.

Table 1 Data source for the two study areas.

\begin{tabular}{lcccc}
\hline \hline & Xuzhou city & & \multicolumn{2}{c}{ Dortmund city region } \\
\cline { 5 - 5 } Data & Date & & Data & Date \\
\hline Landsat MSS & 19.05 .1979 & & Landsat MSS & 29.08 .1975 \\
Landsat TM & 20.09 .1990 & & Landsat TM & 25.05 .1989 \\
Landsat ETM+ & 03.04 .2001 & & Landsat ETM+ & 15.05 .2000 \\
Landsat TM & 12.08 .2005 & Landsat TM & 18.07 .2006 \\
\hline \hline
\end{tabular}




\section{Methods}

\subsection{Land-Cover Classification}

\subsubsection{Classification system}

Prior to LC classification, a modified version of the Anderson classification system ${ }^{18}$ with four LC categories (built-up land, farmland, vegetation, and water body) was established by taking into consideration the spectral characteristics of Landsat images, existing knowledge of LC categories within the study areas, and the objectives of the study (Table 2).

\subsubsection{Supervised classification}

Maximum likelihood classifier (MLC), the most commonly used supervised classification method, was selected to extract LC information from Landsat data as well as to produce a distance image. In order to consider the influence of seasonal change of farmland, the classified image produced by MLC consisted of five classes: built-up land, farmland, bare soil, vegetation, and water body. The distance image represents the Mahalanobis distance between the corresponding pixel in the input continuous raster layer file and signature to which it was classified. In the distance image file, pixels that are most likely to be misclassified have the higher value. ${ }^{19}$

\subsubsection{Classification refinement}

Due to the relatively coarse spatial resolution and spectral similarities of the Landsat images, some pixels were misclassified in the initial classification results after MLC supervised classification. The postclassification refinement can greatly improve the accuracy of results. ${ }^{10,20}$ An expert classifier was used to correct misclassified land-use categories by defining refinement rules and assigning specific thresholds for different classes. As the first step in the classification refinement process, distance image was employed to identify the pixels that were the most likely to be misclassified by defining a specific threshold.

Urban landscape is a complex combination of different LCs such as farmland, impervious surface, vegetation, and water. ${ }^{21,22}$ Some different LC classes may be contained in one pixel of satellite image; it can cause the difficulty for separating one specific LC class from other classes using spectral characteristics. ${ }^{23}$ Mixed pixel problem has been regarded as the main reason for low accuracy of classification. In this study, mixed pixel problem was found between nonvegetation land (built-up and bare soil) and vegetation categories. The IMAGINE subpixel classifier in ERDAS IMAGINE software provides an efficient way to identify the specific material in each pixel. ${ }^{24}$ It can be successfully used to identify a specific material when multiple materials are mixed in one pixel. End members of vegetation were first selected on the Landsat image through visual interpretation. With the aid of a subpixel classifier, a fraction image of vegetation for Landsat image based on selected end members was produced, in which the value of each pixel was expressed by the proportion of vegetation in each pixel. A threshold for extracting vegetation pixels was identified from fraction image by

Table 2 Land-cover (LC) classification scheme.

\begin{tabular}{ll}
\hline \hline LC classes & \multicolumn{1}{c}{ Description } \\
\hline Built-up land & $\begin{array}{l}\text { Residential, commercial services, industrial, transportation, communications, } \\
\text { mixed urban or build-up land, and other urban or built-up lands }\end{array}$ \\
Farmland & Crop fields, pasture, and bare fields \\
Vegetation & $\begin{array}{l}\text { Deciduous forest land, evergreen forest land, mixed forest land, orchards, } \\
\text { groves, vineyards, nurseries, and ornamental horticultural area }\end{array}$ \\
Water body & Permanent open water, lakes, reservoirs, and streams \\
\hline \hline
\end{tabular}


visual interpretation. All misclassified pixels caused by mixed pixel problem were reclassified into correct categories by thresholding.

By using subpixel classifier, the initially misclassified vegetation pixels were separated from nonvegetation class, but some bare soil pixels were misclassified as built-up due to close spectral similarities between these two types in one temporal image. In these two study areas, the farmland represents like bare-soil because of the crop calendars and phenology. The seasonal behavior of crop is a fundamental component of successful image interpretation. The normalized difference vegetation index (NDVI) values derived from multitemporal images were used to aid in separation of bare soil and built-up types based on their phenological characteristics. We have found that farmland areas have high NDVI values during the growing season and low NDVI values during harvesting season. The refinement rule and threshold within framework of expert classifier were defined to reduce the classification errors according to the difference of NDVI values between growing and ungrowing seasons. The bare soil pixels were reclassified into built-up and farmland by using the refinement rule.

Having considered LC characteristics and applications of the study areas, the five LC categories in the final classified images were merged into four classes: built-up, farmland, vegetation, and water body. Although application of subpixel classifier and multitemporal images analysis greatly improved the accuracy of MLC classification, some misclassification pixels were still found in the classified images due to the spectral confusion, especially in the MSS image among the datasets. Some further data, such as digital elevation model (DEM) as well as brightness, greenness, and wetness components, from the tasseled cap transformation (TCT) were incorporated to refine classified results. From the DEM data, the slope value in degree was extracted. In this study, farmland was not expected to be found in the areas with slope higher than $10 \mathrm{deg}$. Therefore, the farmland pixels with slope higher than $10 \mathrm{deg}$ should be reclassified as vegetation. The corresponding rule can be defined in Knowledge Engineer classifier to conduct the refinement. The TCT is a conversion of the original bands of an image into a new set of bands with defined interpretations that are useful for vegetation mapping. ${ }^{25}$ The built-up and bare soil areas have higher values compared with other LC types in the brightness band. In the greenness band, the built-up and bare soil land have lower values, whereas the areas covered by green vegetation have higher values. In the wetness band, the water bodies have higher values. Therefore, we can define the specific thresholds to distinguish different LC classes in each band generated by TCT. In addition, a $3 * 3$ majority filter was applied to remove the salt and pepper appearances in the images. Finally, accurate classified images with four land-use categories were generated.

\subsubsection{Classification accuracy assessment}

In order to evaluate the performance of the classification method and to check whether the results are correct for change detection, an error matrix was carried out to assess the accuracy for classification results. ${ }^{26}$ A total of 200 random points generated by stratified random sampling method in ERDAS was adopted to assess classification accuracy. Finally, the classified data and reference data were compared and statistically represented in the form of error matrices.

\subsection{Change Detection}

Following the LC classification, change detection analysis was used to analyze the patterns of LC change during the study period. Change detection is the process of identifying differences in the states of an object or phenomenon by observing it at different times. ${ }^{27}$ Image differencing, principal component analysis, and postclassification comparison are the most common methods used for change detection. ${ }^{7}$

Postclassification was selected as a change detection method in this study. It involves independently produced spectral classification results from each end of the time interval of interest, followed by a pixel by pixel or segment by segment comparison to detect changes in cover type.$^{28}$ The main advantage of this method lies in the fact that each image is separately classified. This, thereby, minimizes the differences of sensor characteristics, atmospheric effects, solar illumination angle sensor view angle, and vegetation phenology between the dates. ${ }^{29}$ 


\subsection{Analysis of LC Change Pattern}

\subsubsection{Buffer analysis}

Although the LC change trend of the study areas have been quantitatively characterized by using statistic data of LC change, it cannot capture the detailed information about the spatiotemporal pattern of urban growth. In order to address the question of where the urban growth is occurring, GIS-based buffer analysis was applied. The buffer zone areas were established around the existing built-up area by radii of 250,500, 1250, and $1500 \mathrm{~m}$, respectively.

To quantify the pattern of new built-up area, frequency ratio method was implemented using GIS techniques, ${ }^{30,31}$ which can be computed as follows:

$$
\begin{gathered}
\mathrm{FR}=\frac{R_{a}}{R_{b}} . \\
R_{a}=\frac{\mathrm{LC}_{\mathrm{s}}}{\mathrm{LC}_{\mathrm{w}}} . \\
R_{b}=\frac{A_{\mathrm{s}}}{A_{\mathrm{w}}},
\end{gathered}
$$

where $\mathrm{LC}_{\mathrm{s}}$ is the new developed area in the single buffer zone, and $\mathrm{LC}_{\mathrm{w}}$ is the new developed area in the whole buffer zones. $A_{\mathrm{s}}$ is the area of the single buffer zone, and $A_{\mathrm{w}}$ is the area of the whole buffer zones. FR is defined as the ratio of percentage of new developed area in single buffer zone to the percentage of the each buffer zone in the whole buffer zones.

In the case of a relationship between newly developed built-up area and the buffer zone of 0 to $250 \mathrm{~m}$ around the existing built-up area, if the value is larger than 1 , it means that the percentage of new developed built-up area in the buffer zone is higher than that of the whole buffer zones and higher change intensity occurred in this zone, whereas if the value is lower than 1, then it indicates lower change intensity. A value of 1 is an average value for the whole buffer zones. Therefore, it can be used to compare the intensity of built-up change in each buffer zone over various periods.

\subsubsection{Jaggedness degree}

Besides detecting the LC change, there are wide interests and needs to measure and analyze temporal change on geometric forms as a basis for understanding spatial patterns and processes. Compactness is an important concept and index which reflects the regional and urban forms. To measure and monitor urban compactness, we need indicators for capturing the characteristics of land-use development. In this article, the jaggedness degree defined by $\mathrm{Thinh}^{32}$ was employed as the measurement of the compactness of the study areas.

Table 3 Summary of Landsat classification accuracies for study years.

\begin{tabular}{lccccc}
\hline \hline & \multicolumn{2}{c}{ Xuzhou city } & & \multicolumn{2}{c}{ Dortmund city region } \\
\cline { 2 - 3 } \cline { 5 - 6 } Time point & Overall accuracy (\%) & Kappa coefficient & & Overall accuracy (\%) & Kappa coefficient \\
\hline T1 & 82.5 & 0.74 & & 84 & 0.76 \\
T2 & 89 & 0.83 & & 90.5 & 0.86 \\
T3 & 90.5 & 0.86 & & 92 & 0.88 \\
T4 & 90 & 0.85 & & 91.5 & 0.87 \\
\hline \hline
\end{tabular}

Note: Xuzhou city (T1: 1979; T2: 1990; T3: 2001; T4: 2005). Dortmund city region (T1: 1975; T2: 1989; T3: 2000; T4: 2006). 
Current literature in geography and landscape ecology defines usually the compactness of an object as a numerical representation describing how far an object deviates from a standard shape: a circle or a square. For any circle, the following relationship holds: perimeter/ $\operatorname{SQRT}($ Area $)=2 \times \operatorname{SQRT}(\pi)$. This relationship inspires us to use a ratio of the total edge length $P$ to the square root of the total area of all individual settlement areas $A$ for the measurement of the compactness of urban patterns. Let $a_{i}$ be the area and $p_{i}$ be the circumference of the polygons of a settlement pattern $[i=1(1) n]$. The jaggedness degree was defined as follows:

$$
\text { Jaggedness Degree }=\frac{\sum_{i=1}^{n} p_{i}}{2 \sqrt{\pi \sum_{i=1}^{n} a_{i}}} .
$$

\section{Results}

\subsection{Classification Accuracy}

Accuracy assessment results were generated for two study areas (Table 3). The accuracies for these results indicate that the refinement methods proposed in this article are effective in extracting LC information from Landsat images. Therefore, the classified results can be used as data source for postclassification comparison to detect LC change. However, the results generated from MSS images for the two study areas have relatively low accuracy among the dataset. It can be explained by mixed pixels and spectral confusion due to the coarse spatial

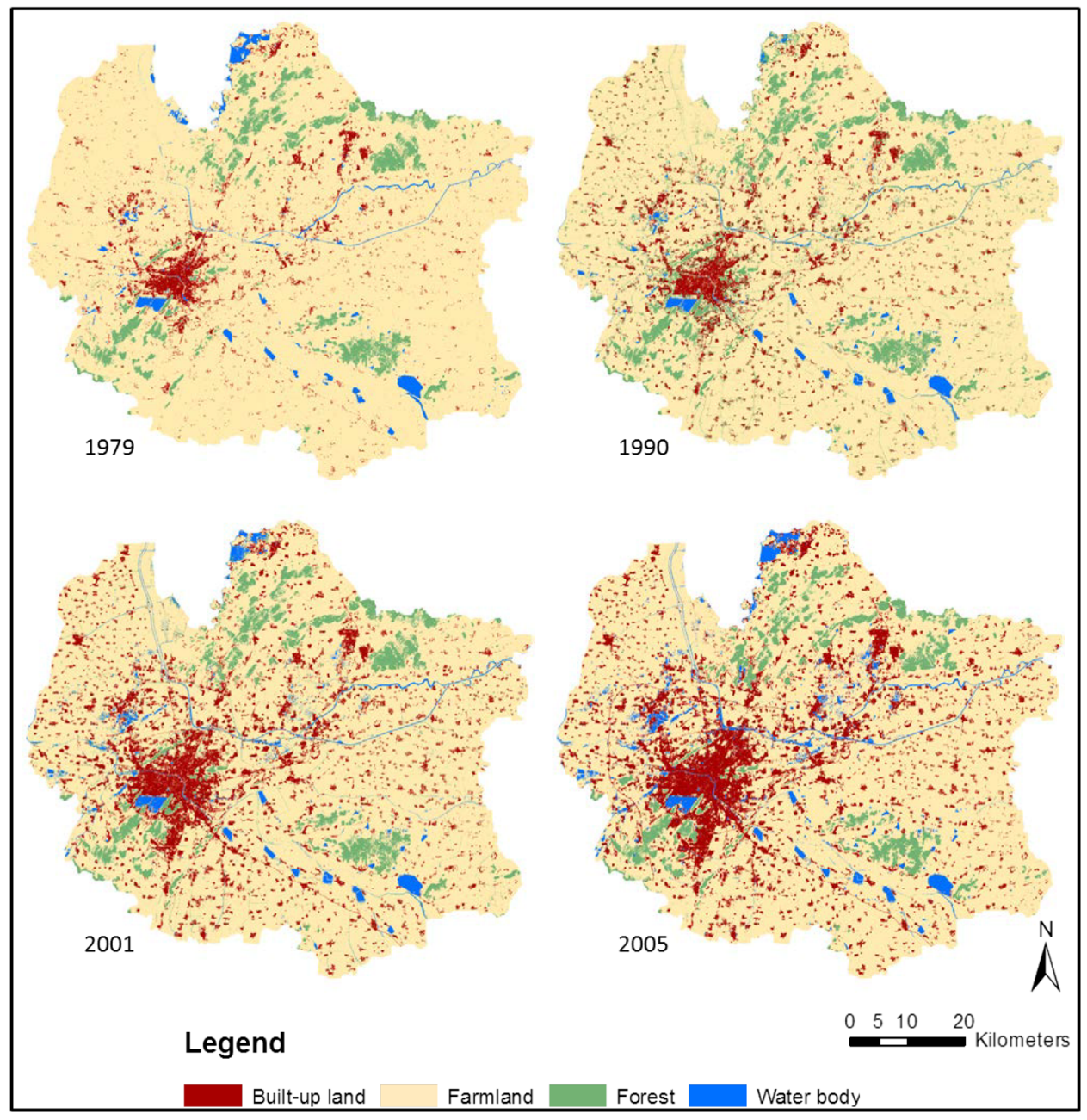

Fig. 2 Classified land-cover (LC) maps of Xuzhou city from 1979 to 2005. 
resolution of MSS image. There will still be some misclassification pixels after classification refinement.

\subsection{Land-Use Change in the Two Study Areas}

The multitemporal LC classification maps for the two study areas are shown in Figs. 2 and 3. The individual class area for the study years are summarized in Tables 4 and 5.

From the overall trend, intense LC change occurred in Xuzhou city and was mainly characterized by a significant increase in built-up land and a gradual decrease in farmland and vegetation. The area of water body increased rapidly due to the waterlogged subsidence in coal-mining areas. The built-up land, as the largest growth type, increased from $128.5 \mathrm{~km}^{2}$ in 1979 to $418.3 \mathrm{~km}^{2}$ in 2005 . Furthermore, the annual rate of growth in the built-up land increased during the latest period (Fig. 4), which indicates that Xuzhou city experienced rapid urban growth with the accelerating speed over the study period. The greater growth speed in built-up land occurred during the period from 1990 to 2005 due to the rapid economic development. The economic reform started in China since late 1970s; after the initial period of around 10 years from centralized planning to market-oriented economic system, the economy of Xuzhou city was moving into the fast lane. Rapid development required more built-up land and industrial workers than ever before, which also led to relatively high-urbanization speed. The incredible pressure of rapid urbanization on nonurban land was reflected by the high loss in farmland and vegetation land. A large amount of nonurban

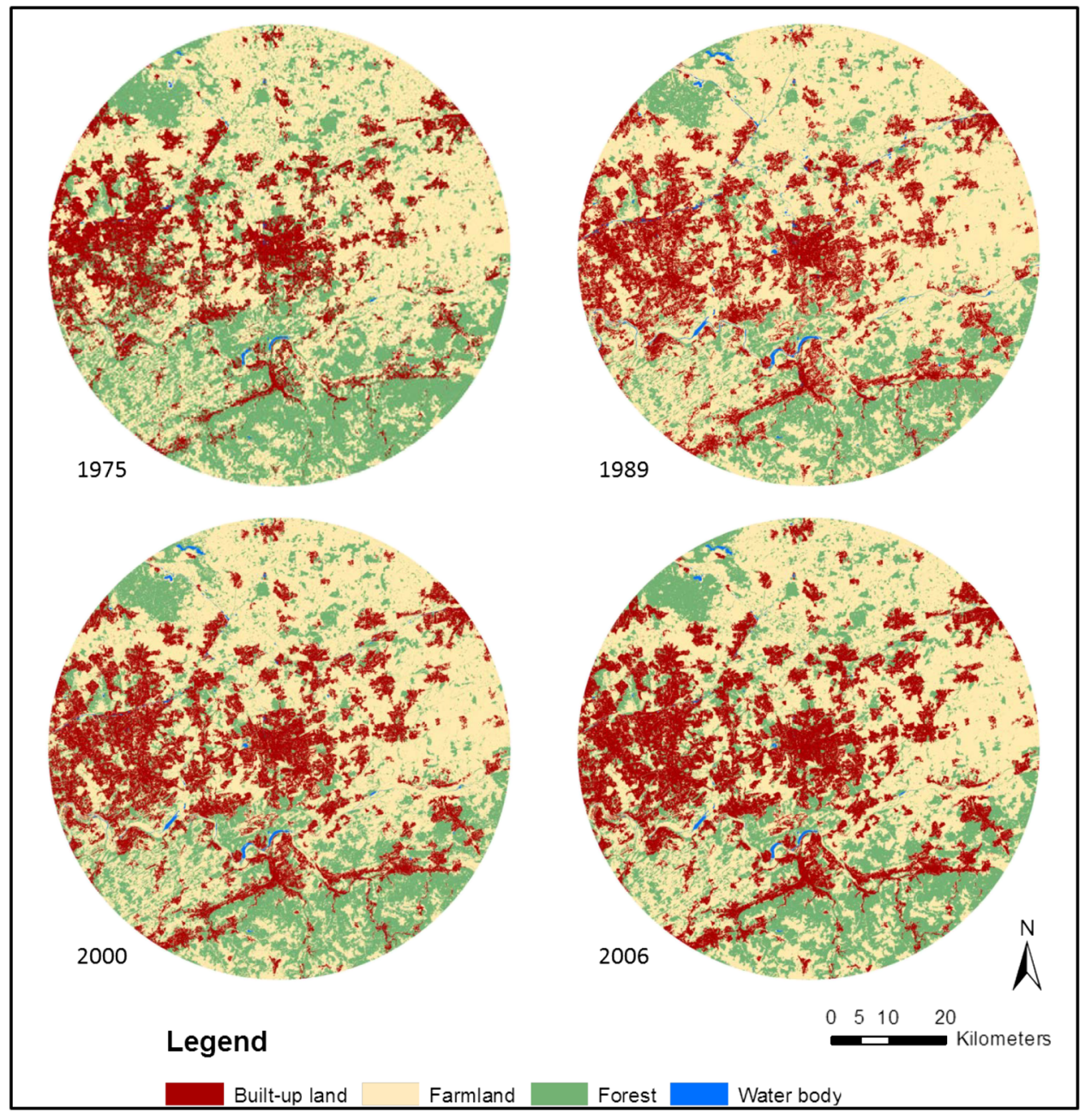

Fig. 3 Classified LC maps of Dortmund city region from 1975 to 2006. 
Table 4 LC statistical data of Xuzhou city.

\begin{tabular}{|c|c|c|c|c|c|c|c|c|}
\hline \multirow[b]{2}{*}{ LC classes } & \multicolumn{2}{|c|}{1979} & \multicolumn{2}{|c|}{1990} & \multicolumn{2}{|c|}{2001} & \multicolumn{2}{|c|}{2005} \\
\hline & $\begin{array}{l}\text { Area } \\
\left(\mathrm{km}^{2}\right)\end{array}$ & $\begin{array}{l}\text { Percent } \\
(\%)\end{array}$ & $\begin{array}{l}\text { Area } \\
\left(\mathrm{km}^{2}\right)\end{array}$ & $\begin{array}{l}\text { Percent } \\
(\%)\end{array}$ & $\begin{array}{l}\text { Area } \\
\left(\mathrm{km}^{2}\right)\end{array}$ & $\begin{array}{l}\text { Percent } \\
(\%)\end{array}$ & $\begin{array}{l}\text { Area } \\
\left(\mathrm{km}^{2}\right)\end{array}$ & $\begin{array}{l}\text { Percent } \\
(\%)\end{array}$ \\
\hline Built-up & 128.5 & 4.44 & 174.6 & 6.03 & 333.4 & 11.51 & 418.3 & 14.44 \\
\hline Farmland & 2462.6 & 85.00 & 2430.2 & 83.88 & 2303.5 & 79.51 & 2230.3 & 76.98 \\
\hline Vegetation & 266.2 & 9.19 & 253.6 & 8.75 & 192.3 & 6.64 & 151.8 & 5.24 \\
\hline Water body & 39.9 & 1.38 & 38.9 & 1.34 & 68.1 & 2.35 & 96.8 & 3.34 \\
\hline
\end{tabular}

Table 5 LC statistical data of Dortmund city region.

\begin{tabular}{|c|c|c|c|c|c|c|c|c|}
\hline \multirow[b]{2}{*}{ LC classes } & \multicolumn{2}{|c|}{1975} & \multicolumn{2}{|c|}{1989} & \multicolumn{2}{|c|}{2000} & \multicolumn{2}{|c|}{2006} \\
\hline & $\begin{array}{l}\text { Area } \\
\left(\mathrm{km}^{2}\right)\end{array}$ & $\begin{array}{l}\text { Percent } \\
(\%)\end{array}$ & $\begin{array}{l}\text { Area } \\
\left(\mathrm{km}^{2}\right)\end{array}$ & $\begin{array}{l}\text { Percent } \\
(\%)\end{array}$ & $\begin{array}{l}\text { Area } \\
\left(\mathrm{km}^{2}\right)\end{array}$ & $\begin{array}{l}\text { Percent } \\
(\%)\end{array}$ & $\begin{array}{l}\text { Area } \\
\left(\mathrm{km}^{2}\right)\end{array}$ & $\begin{array}{l}\text { Percent } \\
(\%)\end{array}$ \\
\hline Built-up & 498.0 & 17.59 & 588.1 & 20.77 & 679.4 & 24.00 & 715.5 & 25.27 \\
\hline Farmland & 1516.1 & 53.55 & 1501.4 & 53.03 & 1442.4 & 50.95 & 1415.3 & 49.99 \\
\hline Vegetation & 806.7 & 28.49 & 730.8 & 25.82 & 698.4 & 24.67 & 688.8 & 24.33 \\
\hline Water body & 10.3 & 0.37 & 10.8 & 0.38 & 10.9 & 0.38 & 11.5 & 0.41 \\
\hline
\end{tabular}

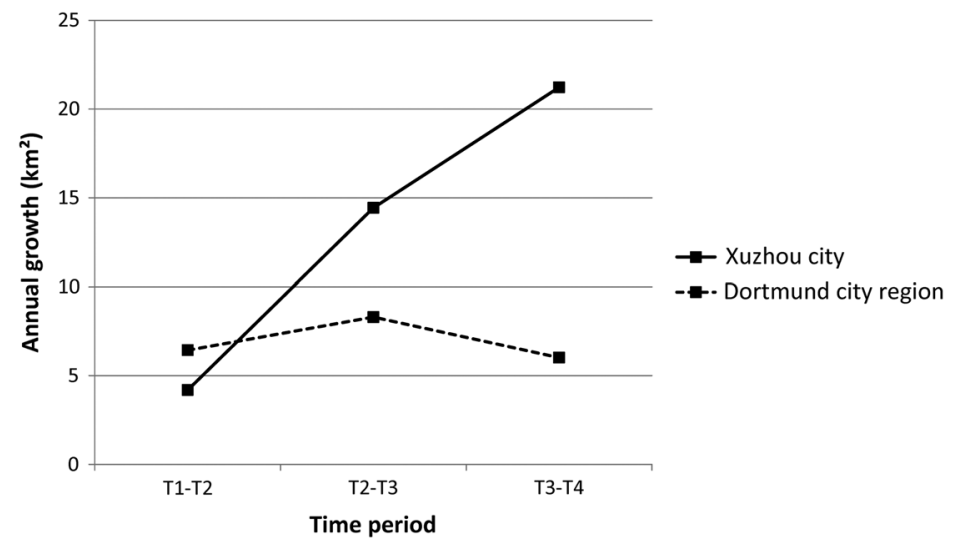

Fig. 4 Annual growth of built-up class.

land was converted into built-up land. The farmland and vegetation decreased by 232 and $114.4 \mathrm{~km}^{2}$, respectively.

Compared with Xuzhou city, Dortmund city region in Germany showed different LC change trends. The built-up area increased at low speed. In 1975, the built-up area was $498 \mathrm{~km}^{2}$, representing $17.59 \%$ of the total area, and increased to $715.5 \mathrm{~km}^{2}$ in 2006 . It has been observed that the growth speed of built-up land was slower than that in Xuzhou city. Moreover, the annual growth rate decreased from 8.30 to $6.02 \mathrm{~km}^{2}$ over two periods, which indicates that the speed of development slowed down. Meanwhile, the corresponding reduction in farmland and vegetation land also slowed down. The trends in LC change for the three important classes, built-up, farmland, and vegetation areas, are shown in Fig. 5. 


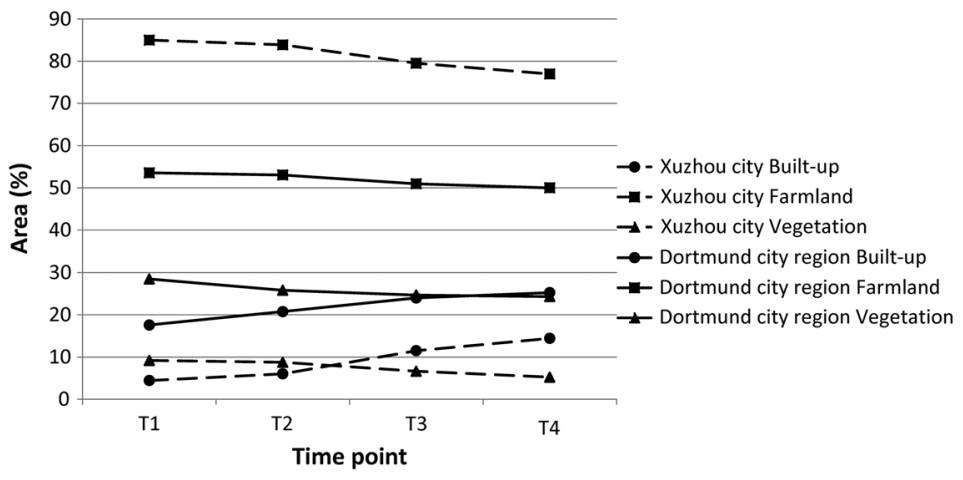

Fig. 5 Area percentage of built-up, farmland, and vegetation classes.

\subsection{Buffer Analysis}

The relationships between change patterns and distance from the existing built-up area were explored to make further analysis of land-use change pattern in both time and space. Figures 6 and 7 represent the percentage of new developed area in each buffer zone to that in the whole buffer zones $\left(R_{a}\right)$. By using FR indicator, the result of buffer zone analysis for the new developed built-up land of the two study areas is shown in Figs. 8 and 9, in which urban expansion and its temporal dynamics are reflected.

In Xuzhou city, overall, the new built-up area mainly focused on the first buffer zone around the existing built-up area with the frequency ratio larger than 1, and as the distance to the existing built-up increased, the frequency of built-up growth decreased until it reached 0 (see Fig. 8). However, the characteristics of spatial pattern of LC change varied with different periods.

For the period of 1979 to 1990 and 1990 to 2001, Fig. 8 shows a rapid decline in the buffer zones from 0 to $500 \mathrm{~m}$ with similar peak values of 2.06 and 2.21, respectively, which suggest that the area experienced the high-intensity change from nonbuilt-up land to built-up land. Furthermore, according to Fig. 6, the new developed built-up land in the first buffer zone accounted for 84.59 and $78.54 \%$ of new developed land occurred in the whole buffer zones, which imply that the urbanization in Xuzhou during these periods mainly concentrated within $250 \mathrm{~m}$ from the existing built-up area. At $500 \mathrm{~m}$, the curves kept a gradual and smooth downtrend with low FR value as the distance increased. The results show that there existed significant correlation between distance to the existing built-up area and development of built-up land. Compared with the two periods mentioned above, the curve for the period of 2001 to 2005 represents a significant change in intensity and magnitude of urbanization, which involved dramatic reduction in frequency ratio value and share of new built-up land within $250 \mathrm{~m}$, while higher FR and proportion values in the outer buffer zone. The differences imply that the active

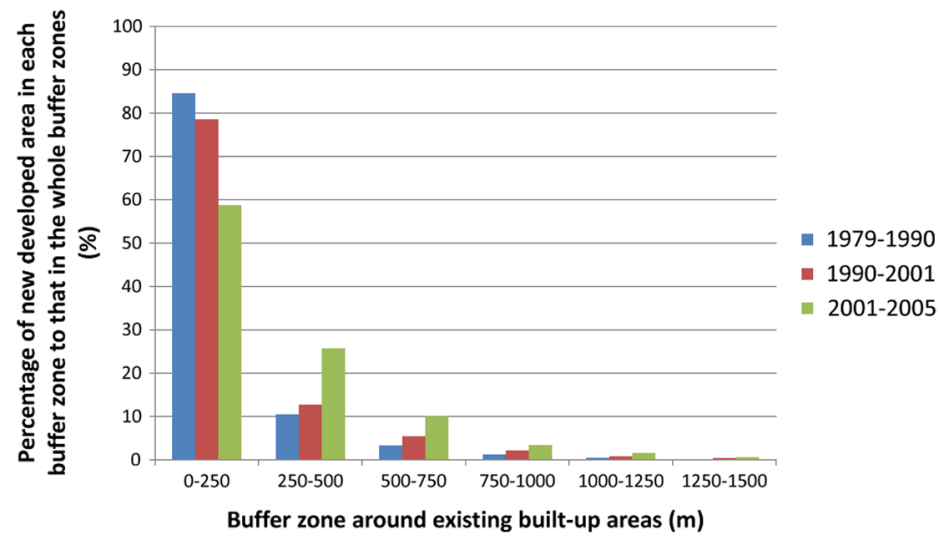

Fig. 6 Change in $R_{a}$ with distance to the existing built-up over Xuzhou city in different time periods. 
$\mathrm{Li}$ and Thinh: Investigation and comparison of land-cover change patterns in Xuzhou city, China...

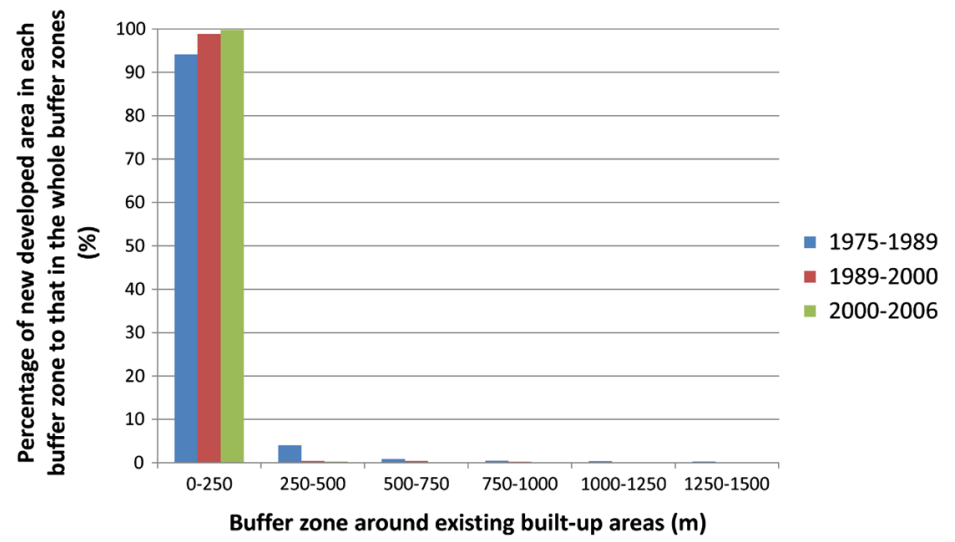

Fig. 7 Change in $R_{a}$ with distance to the existing built-up over Dortmund city region in different time periods.

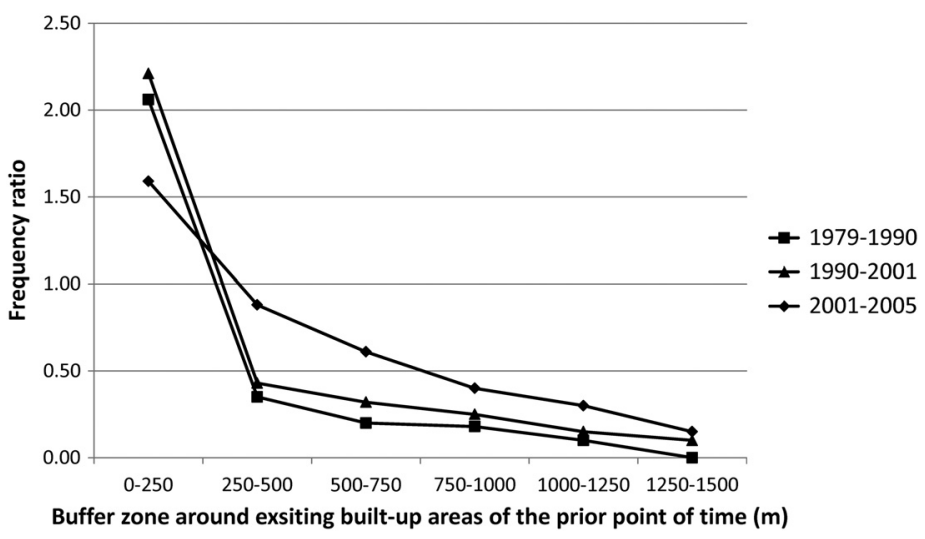

Fig. 8 Change in FR with distance to the existing built-up over Xuzhou city in different time periods.

area for high-intensity development has been expanded to a larger zone, and the effect of distance to the existing built-up on new developed land became weakened during this period. Thus, this finding can be considered as an indication of sprawling urban development.

The results of buffer analysis (Figs. 7 and 9) reflect that the spatiotemporal patterns of builtup growth have similar characteristics both in terms of magnitude and intensity during the period from 1975 to 2006 with high-initial peak values, followed by rapid decline. The peaks of FR

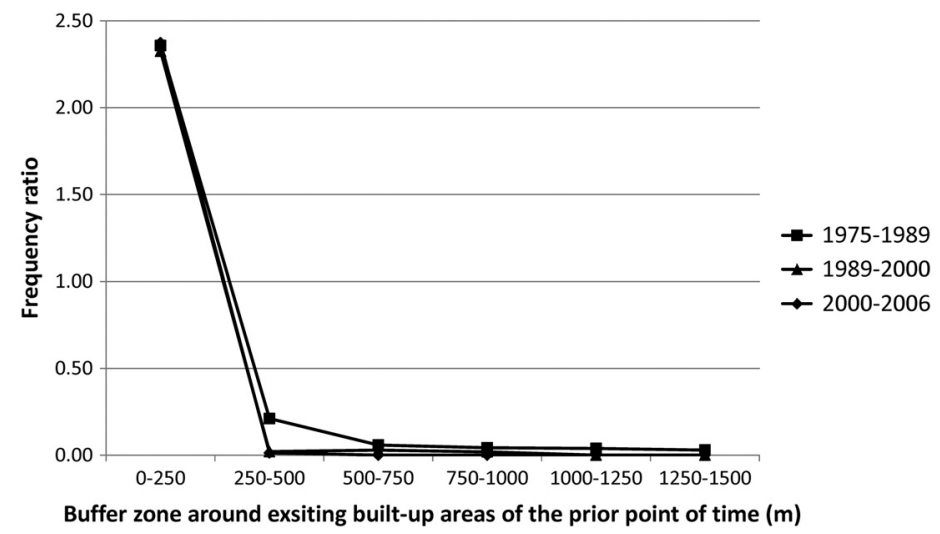

Fig. 9 Change in FR with distance to the existing built-up over Dortmund city region in different time periods. 
Table 6 Jaggedness degrees of the two study areas.

\begin{tabular}{lcccc}
\hline \hline Study area & $\mathrm{T} 1$ & $\mathrm{~T} 2$ & $\mathrm{~T} 3$ & $\mathrm{~T} 4$ \\
\hline Xuzhou city & 55.23 & 55.95 & 56.73 & 58.50 \\
Dortmund city region & 31.15 & 29.72 & 29.36 & 29.34 \\
\hline \hline
\end{tabular}

curves were observed in the range from 0 to $250 \mathrm{~m}$ around the existing built-up area, owning higher peak values than those of Xuzhou city. Beyond $250 \mathrm{~m}$, however, the FR value rapidly declined to approach 0 . This indicates that the intensity of LC change remained at high level near the existing built-up land over study periods. In addition, more than $90 \%$ of the new developed built-up land in the first buffer shown in Fig. 7 suggests that the new developed land is mainly distributed in the suburb area. This trend was getting strengthened over time, which was reflected by the slight increase in proportional value of new built-up land in suburb from 1975 to 2006 .

Comparing the buffer analysis results of the two study areas, they shared certain common characteristics. The development of new built-up areas was related to the distance to the existing built-up area. The shorter the distance was to the existing built-up area, the higher the intensity of LC change. However, the curve of FR values for different periods and study areas reflects different spatiotemporal patterns of LC. In general, for Dortmund city region, the suburb area experienced a higher intensity of urbanization, and a larger proportion of new developed built-up land was concentrated in first buffer zone compared with Xuzhou city. Furthermore, there are other significant differences in variance of share of new developed built-up land over time. The share of new built-up land in suburb decreased over the study period in Xuzhou city, whereas a slight increase in share value was observed in Dortmund city region. These differences in spatiotemporal patterns of LC change show the different urbanization processes the two study areas experienced.

\subsection{Jaggedness Degree}

To further explore the differences between the two study areas, we used the jaggedness degree to quantify and compare urban forms and development patterns. The jaggedness degree (Table 6) shows very distinct spatial differences between these two study areas, which enable a more detailed view of how urban form varied. The jaggedness degree for Dortmund city region is much lower at each time point compared with contemporary jaggedness degree for Xuzhou city, indicating relatively compact urban form for Dortmund city region. The higher jaggedness degree for Xuzhou city means that it has a more dispersed urban form. The urban form of Xuzhou city is characterized by dispersed built-up areas around the main city center, most of which were small-sized rural settlement areas.

Moreover, the temporal changes in jaggedness degrees represent two different urban development trends. The slight decrease in jaggedness degrees during study period indicates that Dortmund city region underwent compact development, which is also reflected by the buffer analysis that most of new developed built-up land occurred around the existing built-up land. Dortmund city region experienced effective growth to produce big and dense urban cores for providing the necessary services and management facilities for its inhabitants. Whereas the situation is just opposite in Xuzhou city; an increase in jaggedness degrees for Xuzhou city suggests that it had dispersed development trend. A jump on value from T3 (2001) to T4 (2005) shows the increased sprawling development trend, which can be explained by the fact of rapid urbanization and increasing new dispersed built-up land.

\section{Discussion and Conclusions}

\subsection{Spatiotemporal Characteristics of Urban Expansion}

Understanding the changing urban growth pattern in urbanization processes is important in urban development planning and sustainable growth management. ${ }^{33}$ The study presented 
wide comparisons between Xuzhou city and Dortmund city region in both the amount of LC classes and urban growth pattern in order to provide a better understanding of different underlying processes. Although there are some common features, different areas adopt different paths due to their different cultural backgrounds and developmental stages, resulting in different land-use patterns. ${ }^{34}$

The results of our analysis confirmed a general trend of relatively slow urban growth process in developed countries compared with that in developing countries. The development in Dortmund city region was characterized by the smooth growth with continuous patches, which resulted in compact development during the study period. This corresponds with the findings from other cities in the developed countries. ${ }^{35,36}$ The stable and slow increase in urban area indicates that the urbanization process continued along the path of historical trends without rapid change in driving factors, which have a significant influence on the urban growth. The variable of distance to existing urban area had a strong impact on urban growth pattern, so that newly urbanized areas were observed very close to existing urban areas and most of them focused within $250 \mathrm{~m}$ away from existing urban. The urban growth in Dortmund city region was more focused on the extension of existing urban areas and increasing connection of recent individual urban patches close to the urban cores. As a result, the urban pattern was growing more compact.

In contrast to Dortmund city region, Xuzhou city was characterized by the rapid urbanization. The similar trends of urbanization are revealed by the case studies on other areas in developing countries. ${ }^{6,10,17,37}$ However, urban growth patterns varied across different regions and countries during different developing periods. By combining buffer analysis and jaggedness degree with land-use change detection, this study identifies spatial characteristics of the urban development of Xuzhou city, which can be divided into the following three phases:

\subsubsection{Initial rapid development phase (1979 to 1990)}

During this period, there was a rapid decrease in intensity and share of new developed built-up land with increasing distance to the existing built-up land outside the first buffer. This finding has also been found by some studies for other cities; for example, a GIS-based buffer analysis of Shanghai revealed the outskirts of the city that are immediately adjacent to the former urban area which have the highest expansion intensities. ${ }^{38}$ In Lianyungang city in China, the highest urban growth density zone located close to the existing urban area. ${ }^{39}$ The infrastructure and transportation conditions were improved in order to provide a basis for rapid economic development, which resulted in the new developed built-up land around the city center. This was further supported by the newly launched rural land reform that introduced the household responsibility system, and at the end of 1970s, the expansion of built-up land was significant in the rural area. However, built-up land expansion was constrained by policy and insufficient infrastructure in Xuzhou city. For example, before the end of 1980s, a nationwide strict policy for population constrained the rapid development. The resident was not allowed to leave his or her birthplace to seek employment, receive education, or settle in another city without official certification, which depressed the population growth and urban expansion. ${ }^{6}$ Thus, when comparing with case studies from other developing countries, where uncontrolled population growth caused problematic land use,,$^{10,40}$ the policies were used to effectively control population migration and sprawl of illegal settlements. As witnessed, the expansion area was small in both urban and rural areas due to the insufficient infrastructure, relatively low-economic level, and strict population policy.

\subsubsection{Transition phase (1990 to 2001)}

The slight decrease in the share of new built-up land in the first buffer zone was observed during this period, because the expansion region for urbanization slowly moved outward. This finding may be due to the fact that the development of the transportation system and infrastructure provided a good opportunity for large-scale construction around the city center such as industrial parks. ${ }^{11,41}$ Spatially, the expansion of the new built-up land occurred mainly toward the east and south, along the main roads, which formed main growth axes of Xuzhou city. Like other areas in developing countries, ${ }^{17,36,42}$ rapid industrialization and urbanization resulted in the rising demand for built-up land, thus much farmland has been converted into built-up land, and 
the extent of the main city continued to increase along the monocentric development trend. On the other hand, because of the deepening urbanization and flexible population mobility policy, an increase in in-migration and natural population has led to rapid population growth in the city. As a result, the conflict between limited land resource nearby the city center and rapid urban sprawl became more apparent, which is consistent with the widely acknowledged conflict between rapid development and limited land resource in developing countries. The analysis of LC change in Dhaka Metropolitan of Bangladesh indicated that the urban expansion caused amplified pressure on the agricultural and vegetation lands around the city. ${ }^{10}$ The urban growth patterns in Hanoi and Shanghai also revealed the significant conflict between rapid urban growth and land resources. ${ }^{43}$ In order to solve the conflict, the urbanization mode has begun the transformation from the high intensity, small expansion region to extensity and wide range.

\subsubsection{Extensive phase (2001 to 2005)}

Compared with the previous phases, the most significant difference is the variation of the urban expansion zone. The urban expansion zone rapidly moved outward for the extensive development since 2001, the active area for development was not constrained to be in the main city area, and more and more new built-up land occurred in subcenter areas. In contrast, a comparison of urban growth in 25 global cities suggested that most cities in developing countries have appreciable amounts of newly developed urban land in the city core,${ }^{36}$ which was different from our finding. In order to promote regional economic integration as well as to avoid the "big-pancake" form generated, which can result in a series of problems such as traffic jams, excessive sprawl, lack of green space, increased "heat island" effect, and air pollution in developing countries, ${ }^{2,44}$ the polycentric development has been proposed as a new planning policy to guide the future development in Xuzhou since 2001. The region was characterized by one center (former city center), two main development axes (southeast and east directions), and several connected regions around the main city center. Therefore, more active areas for development of Xuzhou urban have been generated, and the focus of development has been shifted from the city center to the whole Xuzhou region. The establishment of closer link between the former city center and several small connected regions led to the rapid development of these areas. The similar trends can also be observed in some big cities in China, such as Shanghai and Hangzhou, in which the linkages between former city cores and new developed regions are getting closer to promote regional economic integration and high efficiency of land use. ${ }^{6,45}$

In summary, the spatiotemporal LC patterns of the two study areas show different trends. This can be explained by the significant differences between Xuzhou city and Dortmund city region in socioeconomic situations and stages of urbanization.

\subsection{Development Implication}

The need for sustainable cities is readily apparent in recent years. There are evidences indicating a strong link between urban form and sustainable development, although it is not simple and straightforward. ${ }^{46}$ It can be seen that the urban development in Dortmund city region was more compact and generally extending around the existing built-up area, whereas the development in Xuzhou city was more dispersed. Dispersed urban expansion may cause much more ecological and environmental problems than a more compact pattern. ${ }^{47}$

Compact development presented in Dortmund city region has been considered as a sustainable development trend in reducing the negative effects of dispersed development and in guiding urban development to sustainability. ${ }^{48}$ Thus, the urban growth pattern of Dortmund city region could be valuable for Xuzhou city to solve a series of environmental and socioeconomic problems caused by sprawl and "leapfrog-style" urban development such as the gap of urban development between the city core and subcenter areas, the conflict between limited land resources and high pressure of urbanization, and so on. Some policies and measures should be implemented to generate compact form, for example, in-fill development or qualified brownfield development. In addition, the attraction of subcenters areas for urban growth needs to be emphasized in order to form polycentric development. 


\subsection{Methodological Implications}

The quality and outcome of LC change analysis are strongly dependent on the LC classification maps, which are generated using classification methods. Therefore, a suitable classification method plays an important role in this analysis. ${ }^{49,50}$ The combination of subpixel classifier and multiple NDVI is an effective way for classifying urban LC from remote-sensing images. The foundation of the methods is Vegetation-Impervious Surface-Soil (V-I-S) model, which provides a more realistic depiction of the spatial LC arrangement in the study areas. ${ }^{18}$ It has proven to be useful in urban RS, since it is based on the physical compositions of the urban environment. ${ }^{48,51}$ In this study, the implementation of V-I-S model consisted of two steps: (1) subpixel classification; and (2) multiple NDVI values comparison. Subpixel classifier represents the value of each cell in terms of degree of specific land-use type, which allows for robust and potentially more accurate spatiotemporal modeling. It was applied to solve the mixed pixel problem between vegetation and built-up or soil. However, soil and built-up types were difficult to be clearly separated due to the similar spectral values. Comparison of multiple NDVI values derived from multitemporal remote-sensing images is a useful method to separate these two classes.

In this article, not only changes in the area of each LC type, but also, importantly, the LC change pattern was detected through spatial analysis. It is crucial in providing better understanding of how the urban grows and the factors underlying the urbanization process. "Everything is related to everything else, but near things are more related than distant things." The first law of geography by Tobler is of central significance for understanding urban dynamics. ${ }^{52}$ Buffer analysis identified the regularity of LC change patterns with the distance to existing built-up areas. Near-existing built-up land has a stronger impact on the development of built-up land than distant one. In this study, we used $250 \mathrm{~m}$ as distance increment for each buffer zone. Scale is a central concept in describing and explaining the complex hierarchical organization of the geographic world. ${ }^{53}$ In order to obtain more detailed information of how the urban grows as distance varies, it is necessary to further examine growth characteristics at a smaller scale of distance interval for buffer analysis.

The analysis also highlighted the capability of jaggedness degree for better understanding the urban growth pattern. The assessment of urban form can also be carried out by using some common landscape metrics. ${ }^{54}$ However, jaggedness degree is more sensitive to the compactness of urban forms. If the urban area grows spatially more compact, then the degree decreases. It is important to notice that the variation of jaggedness degree is related to the buffer analysis results over the study period. During the period of 2001 to 2005 in Xuzhou city, the marked increase in share and intensity of new developed urban area in outer buffer zone was reflected by the jump of jaggedness degree. Moreover, the continuous decrease in the jaggedness degree was a quantitative proof for the high share and intensity in the first buffer zone for Dortmund city region.

In summary, the study demonstrated that the methods adopted in this article have a potential to produce accurate LC maps and to achieve a better understanding of the spatial and temporal dynamics of urban growth, which can be used to support land management and policy decisions aimed at sustainable development.

\section{Acknowledgments}

This study was supported by the National Natural Science Foundation of China (Grant No. 41201166) and China Scholarship Council (No. 2010642012). The authors would like to thank the editor and anonymous reviewers for their valuable comments and suggestions that improved this article.

\section{References}

1. J. Han et al., "Application of an integrated system dynamics and cellular automata model for urban growth assessment: a case study of Shanghai, China," Landscape Urban Plann. 91(3), 133-141 (2009), http://dx.doi.org/10.1016/j.landurbplan.2008.12.002.

2. S. Chen et al., "Remote sensing and GIS based integrated analysis of coastal changes and their environmental impacts in Lingding Bay, Pearl River Estuary, South China," Ocean Coast Manage. 48(1), 65-83 (2005), http://dx.doi.org/10.1016/j.ocecoaman.2004.11.004. 
3. J. Xiao et al., "Evaluating urban expansion and land use change in Shijiazhuang, China, by using GIS and remote sensing," Landscape Urban Plann. 75(1-2), 69-80 (2006), http://dx .doi.org/10.1016/j.landurbplan.2004.12.005.

4. P. H. Verburg et al., "Determinants of land use change pattern in the Netherlands," Environ. Plann. B: Plann. Des. 31(1), 125-150 (2004), http://dx.doi.org/10.1068/b307.

5. M. H. Tan et al., "Urban land expansion and arable land loss in China-a case study of Beijing-Tianjin-Hebei region," Land Use Policy 22(3), 187-196 (2005), http://dx.doi.org/ 10.1016/j.landusepol.2004.03.003.

6. $\mathrm{K}$. Wu and $\mathrm{H}$. Zhang, "Land use dynamics, built-up land expansion patterns, and driving forces analysis of the fast-growing Hangzhou metropolitan area, eastern China (19782008)," Appl. Geogr. 34, 137-145 (2012), http://dx.doi.org/10.1016/j.apgeog.2011.11.006.

7. D. Lu et al., "Change detection techniques," Int. J. Remote Sens. 25(12), 2365-2401 (2004), http://dx.doi.org/10.1080/0143116031000139863.

8. R. Pelorosso, A. Leone, and L. Boccia, "Land cover and land use change in the Italian central Apennines: a comparison of assessment methods," Appl. Geogr. 29(1), 35-48 (2009), http://dx.doi.org/10.1016/j.apgeog.2008.07.003.

9. F. Yuan et al., "Land cover classification and change analysis of the Twin Cities (Minnesota) Metropolitan Area by multi-temporal Landsat remote sensing," Remote Sens. Environ. 98(2-3), 317-328 (2005), http://dx.doi.org/10.1016/j.rse.2005.08.006.

10. A. M. Dewan and Y. Yamaguchi, "Land use and land cover change in Greater Dhaka, Bangladesh: using remote sensing to promote sustainable urbanization," Appl. Geogr. 29(3), 390-401 (2009), http://dx.doi.org/10.1016/j.apgeog.2008.12.005.

11. J. Deng et al., "Spatio-temporal dynamics and evolution of land use change and landscape pattern in response to rapid urbanization," Landscape Urban Plann. 92(3-4), 187-198 (2009), http://dx.doi.org/10.1016/j.landurbplan.2009.05.001.

12. Xuzhou Municipal Bureau of Statistics, Statistical Yearbook of Xuzhou City (2005), China Statistical Press, Beijing (2006) (in Chinese).

13. D. R. Oetter et al., "Land cover mapping in an agricultural setting using multi seasonal Thematic Mapper data," Remote Sens. Environ. 76(2), 139-155 (2000), http://dx.doi .org/10.1016/S0034-4257(00)00202-9.

14. S. Ross et al., "Land-cover change detection using multi-temporal MODIS NDVI data," Remote Sens. Environ. 105(2), 142-154 (2006), http://dx.doi.org/10.1016/j.rse.2006.06.018.

15. S. Günthert, M. Wieland, and A. Siegmund, "Change detection analysis for assessing the vulnerability and protective effect of beach forests in case of the Tsunami 2004 in Thailand," Photogramm. Fernerkun. Geoinf. 2011(4), 247-260 (2011), http://dx.doi.org/10.1127/ $1432-8364 / 2011 / 0086$.

16. P. S. Chavez, "An improved dark-object subtraction technique for atmospheric scattering correction of multispectral data," Remote Sens. Environ. 24(3), 459-479 (1988), http://dx .doi.org/10.1016/0034-4257(88)90019-3.

17. C. N. Mundia and M. Aniya, "Analysis of land use/cover changes and urban expansion of Nairobi city using remote sensing and GIS," Int. J. Remote Sens. 26(13), 2831-2849 (2005), http://dx.doi.org/10.1080/01431160500117865.

18. R. Anderson et al., A Land Use and Land Cover Classification System For Use With Remote Sensor Data, U.S. Geological Survey, Washington, DC (1976).

19. D. Lu and Q. Weng, "Spectral mixture analysis of the urban landscape in Indianapolis with Landsat ETM+ Imagery," Photogramm. Eng. Remote Sens. 70(9), 1053-1062 (2004), http://dx.doi.org/10.14358/PERS.70.9.1053.

20. P. M. Harris and S. J. Ventura, "The integration of geographic data with remotely sensed imagery to improve classification in an urban area," Photogramm. Eng. Remote Sens. 61(8), 993-998 (1995).

21. M. K. Ridd, "Exploring a V-I-S (vegetation-impervious surface-soil) model for urban ecosystem analysis through remote sensing: comparative anatomy for cities," Int. J. Remote Sens. 16(12), 2165-2185 (1995), http://dx.doi.org/10.1080/01431169508954549.

22. M. Braun and M. Herold, "Mapping imperviousness using NDVI and linear spectral unmixing of ASTER data in the Cologne-Bonn region (Germany)," Proc. SPIE 5239, 274-284 (2004). 
23. M. Ji and J. R. Jensen, "Effectiveness of subpixel analysis in detecting and quantifying urban imperviousness from Landsat Thematic Mapper imagery," Geocarto Int. 14(4), 33-41 (1999), http://dx.doi.org/10.1080/10106049908542126.

24. L. Daniel et al., "Quantifying and describing urbanizing landscapes in the northeast United States," Photogramm. Eng. Remote Sens. 68(10), 1083-1090 (2002).

25. C. C. Dymond, D. J. Mladenoff, and V. C. Radeloff, "Phenological differences in tasseled cap indices improve deciduous forest classification," Remote Sens. Environ. 80(3), 460-472 (2002), http://dx.doi.org/10.1016/S0034-4257(01)00324-8.

26. G. Foody, "Status of land cover classification accuracy assessment," Remote Sens. Environ. 80(1), 185-201 (2002), http://dx.doi.org/10.1016/S0034-4257(01)00295-4.

27. A. Singh, "Review article: digital change detection techniques using remotelysensed data," Int. J. Remote Sens. 10(6), 989-1003 (1989), http://dx.doi.org/10.1080/ 01431168908903939.

28. P. Coppin et al., "Review article digital change detection methods in ecosystem monitoring: a review," Int. J. Remote Sens. 25(9), 1565-1596 (2004), http://dx.doi.org/10.1080/ 0143116031000101675 .

29. J. F. Mas, "Monitoring land-cover changes: a comparison of change detection techniques," Int. J. Remote Sens. 20(1), 139-152 (1999), http://dx.doi.org/10.1080/014311699213659.

30. S. Lee and J. A. Talib, "Probabilistic landslide susceptibility and factor effect analysis," Environ. Geol. 47(7), 982-990 (2005), http://dx.doi.org/10.1007/s00254-005-1228-z.

31. S. Park et al., "Prediction and comparison of urban growth by land suitability index mapping using GIS and RS in South Korea," Landscape Urban Plann. 99(2), 104-114 (2011), http://dx.doi.org/10.1016/j.landurbplan.2010.09.001.

32. N. X. Thinh, "Entwicklung von AML-Programmen zur räumlichen Analyse der Flächennutzungsmuster von 116 kreisfreien Städten in Deutschland," Photogramm. Fernerkun. Geoinf. 2002(6), 409-422 (2002).

33. J. Cheng and I. Masser, "Understanding spatial and temporal processes of urban growth: cellular automata modeling," Environ. Plann. B: Plann. Des. 31(2), 167-194 (2004), http:// dx.doi.org/10.1068/b2975.

34. B. J. L. Berry, "City size distributions and economic development," Econ. Dev. Cult. Change. 9(4), 573-588 (1961), http://dx.doi.org/10.1086/edcc.1961.9.issue-4.

35. M. Luck and J. Wu, "A gradient analysis of urban landscape pattern: a case study from the Phoenix metropolitan region, Arizona, USA," Landscape Ecol. 17(4), 327-339 (2002), http://dx.doi.org/10.1023/A:1020512723753.

36. A. Schneider and C. E. Woodcock, "Compact, dispersed, fragmented, extensive? A comparison of urban growth in twenty-five global cities using remotely sensed data, pattern metrics and census information," Urban Stud. 45(3), 659-692 (2008), http://dx.doi.org/ 10.1177/0042098007087340.

37. R. C. Estoque and Y. Murayama, "Landscape pattern and ecosystem service value changes: implications for environmental sustainability planning for the rapidly urbanization summer capital of the Philippines," Landscape Urban Plann. 116, 60-72 (2013), http://dx.doi.org/ 10.1016/j.landurbplan.2013.04.008.

38. X. Li, L. Zhang, and C. Liang, "A GIS-based buffer gradient analysis on spatio-temporal dynamics of urban expansion in Shanghai and its major satellite cities," Procedia Environ. Sci. 2, 1139-1156 (2010), http://dx.doi.org/10.1016/j.proenv.2010.10.123.

39. Y. Shi et al., "Characterizing growth types and analyzing growth density distribution in response to urban growth patterns in peri-urban areas of Lianyungang City," Landscape Urban Plann. 105(4), 425-433 (2012), http://dx.doi.org/10.1016/j.landurbplan.2012.01.017.

40. A. Geymen and I. Baz, "Monitoring urban growth and detecting land-cover changes on the Istanbul metropolitan area," Environ. Monit. Assess. 136(1-3), 449-459 (2008), http://dx .doi.org/10.1007/s10661-007-9699-x.

41. R. Bhagyanagar et al., "Land use/land cover change and urban expansion during 1983-2008 in the coastal area of Dakshina Kannada district, South India," J. Appl. Remote Sens. 6(1), 063576 (2012), http://dx.doi.org/10.1117/1.JRS.6.063576.

42. Z. Zheng et al., "Analysis of land use and cover change in Sichuan province, China," J. Appl. Remote Sens. 6(1), 063587 (2012), http://dx.doi.org/10.1117/1.JRS.6.063587. 
43. H. M. Pham, Y. Yamaguchi, and T. Q. Bui, "A case study on the relation between city planning and urban growth using remote sensing and spatial metrics," Landscape Urban Plann. 100(3), 223-230 (2011), http://dx.doi.org/10.1016/j.landurbplan.2010.12 .009 .

44. F. Li et al., "Comprehensive concept planning of urban greening based on ecological principles: a case study in Beijing, China," Landscape Urban Plann. 72(4), 325-336 (2005), http://dx.doi.org/10.1016/j.landurbplan.2004.04.002.

45. L. Cui and J. Shi, "Urbanization and its environmental effects in Shanghai, China," Urban Clim. 2, 1-15 (2012), http://dx.doi.org/10.1016/j.uclim.2012.10.008.

46. X. Li, Q. Yang, and X. Liu, "Discovering and evaluating urban signatures for simulating compact development using cellular automata," Landscape Urban Plann. 86(2), 177-186 (2008), http://dx.doi.org/10.1016/j.landurbplan.2008.02.005.

47. P. Zhao, "Sustainable urban expansion and transportation in a growing megacity: consequences of urban sprawl for mobility on the urban fringe of Beijing," Habitat Int. 34(2), 236-243 (2010), http://dx.doi.org/10.1016/j.habitatint.2009.09.008.

48. X. Li and A. G. O. Yeh, "Modelling sustainable urban development by the integration of constrained cellular automata and GIS," Int. J. Geogr. Inf. Sci. 14(2), 131-152 (2000), http://dx.doi.org/10.1080/136588100240886.

49. D. Lu et al., "Regional mapping of human settlements in southeastern China with multisensor remotely sensed data," Remote Sens. Environ. 112(9), 3668-3679 (2008), http://dx .doi.org/10.1016/j.rse.2008.05.009.

50. M. Liberti et al., "Mapping badland areas using LANDSAT TM/ETM satellite imagery and morphological data," Geomorphology 106(3-4), 333-343 (2009), http://dx.doi.org/10 .1016/j.geomorph.2008.11.012.

51. H. Setiawan et al., "Assessing the applicability of the V-I-S model to map urban land use in the developing world: case study of Yogyakarta, Indonesia," Comput. Environ. Urban Syst. 30(4), 503-522 (2006), http://dx.doi.org/10.1016/j.compenvurbsys.2005.04.003.

52. W. R. Tobler, "A computer movie simulating urban growth in the Detroit region," Econ. Geogr. 46, 234-240 (1970), http://dx.doi.org/10.2307/143141.

53. D. G. Marceau, "The scale issue in social and natural sciences," Can. J. Remote Sens. 25(4), 347-356 (1999).

54. M. Herold, N. C. Goldstein, and K. C. Clarke, "The spatio-temporal form of urban growth: measurement, analysis and modeling," Remote Sens. Environ. 86(3), 286-302 (2003), http://dx.doi.org/10.1016/S0034-4257(03)00075-0.

Cheng $\mathbf{L i}$ is a $\mathrm{PhD}$ candidate in the Department of Spatial Information Management and Modelling. He received a master's degree in cartography and geographic information systems at China University of Mining and Technology. He has been funded by the China Scholarship Council to conduct PhD study at TU Dortmund University since 2010. His current research focuses on monitoring and analysis of land-use change using satellite images, GIS, and cellular automata modeling.

Nguyen Xuan Thinh has been professor in the Department of Spatial Information Management and Modelling since 2011. From 2006 to 2010, he was privatdozent in geoinformatics and deputy of the Department Geoinformation of the Leibniz Institute of Ecological and Regional Development. Using mathematics, multiple criteria decision analysis, geographic information science, and remote sensing, he is working on the development of methods for analysis, assessment, and simulation of urban dynamics with a view to sustainable development and eco-efficiency. 